\title{
The systematics of sponges
}

\author{
Frederick R. Schram
}

Institute for Biodiversity and Ecosystem Dynamics, University of Amsterdam, Mauritskade 57, 1092 AD Amsterdam, Netherlands.

Review of: Systema Porifera, edited by J. N. A. Hooper and R. W. M. van Soest. Kluwer Academic Publ., Dordrecht, Netherlands, 2002, 1708 pp., ISBN 0-306-47260-0

This seems to be a time for the publication of big compendia. One would have thought that in this age of the internet one would be turning to convenient web-sites to find the latest catalogues of data and information about biodiversity of animal groups. Indeed, such do exist, and many of them are remarkably detailed and informative. Nevertheless, there has been a steady stream lately of traditional hardcopy volumes presenting systematic and taxonomic overviews of various groups of animals. This handsome two-volume set is amongst the latest example of these kinds of books to appear.

There are approximately 15,000 species of living sponges - in no way to be considered a small or minor phylum. This diversity does not accord with the false impression that students may receive when, all too often, sponges are amongst the first phyla covered in an invertebrate zoology course with but a day or two at most devoted to them. Systema Porifera does not pretend to cover all those 15,000 species, but it does catalogue the 680 genera of sponges distributed between 127 families, 25 [!] orders, and 3 classes (some would even say 2 phyla, if some of the conclusions derived from molecular sequence data are to be believed). The first and largest volume contains a short, general introduction and a review of the Demospongia, by far the largest of the classes of Porifera. The second volume takes up the Hexactinelida and Calcarea, as well as the fossil Archaeocyatha and Sphinctozoa. The 6-year program that assembled this treatise involved coordinating 45 workers in 17 countries from around the world, a truly international effort.

The emphasis of this work is on the living sponges, and the international team's expressed goal was to stabilize the supra-specific taxonomy of Porifera. They have achieved this within a standardized format. Each genus (sometimes sub-genera as well) has a separate section devoted to it that includes a synonymy of the genus, designation of the type species, a short concise definition focusing on distinctive apomorphies, a more elaborate diagnosis to help identify the genus, an outline of the distribution, and a fairly detailed description of the type species of that genus. This last section contains a synonymy of the species, a list of the material examined with clear designation of the type's catalogue number and depository, a description of that species, and finally an appended set of remarks that take up a history of taxonomic and phylogenetic issues. A really handy feature is that each genus generally is illustrated with SEM and fairly good quality light microscopy photographs of the type material, augmented with drawings where appropriate. All this is amplified with a series of ordinal and familial keys to assist the user with identifications.

An interesting aspect of the second volume is the review provided of the fossil sphinctozoans, or chambered sponges, and the Archaeocyatha. Though these particular chapters are not as detailed as those dealing with living material, they are nonetheless highly informative. This is especially true for the 
archaeocyathans, which contains the detailed survey of that group that has been badly needed for some time. Until a revision of the well-known Treatise on Invertebrate Paleontology for sponges is published, this chapter will serve as a good reference for that group.

The bibliography lists throughout the books are complete and form a valuable asset, and the index of taxonomic names duplicated at the end of each volume is also quite useful.

Books like this are wondrous pieces of work. Some scientists may look down their noses at a compendium like this; such would be foolish to do. The compilation of information to produce such a treatise represents a staggering effort. The editors must be complemented on seeing the project through to completion. To have this kind of information available in one place will form a real stimulus to further understanding of sponge biodiversity. Someday, I suspect that Systema Porifera will form the basis of a more detailed web-site extending down to species level. The framework for such is implicit within the format of these books. However, until that happens this pair of volumes will more than suffice to lead any interested person into the intricacies of sponge taxonomy and nomenclature. We need more compendia such as this.

The price, all things considered, is reasonable $€ 625$, a mere 36 cents a page.

Received: 15 July 2003 